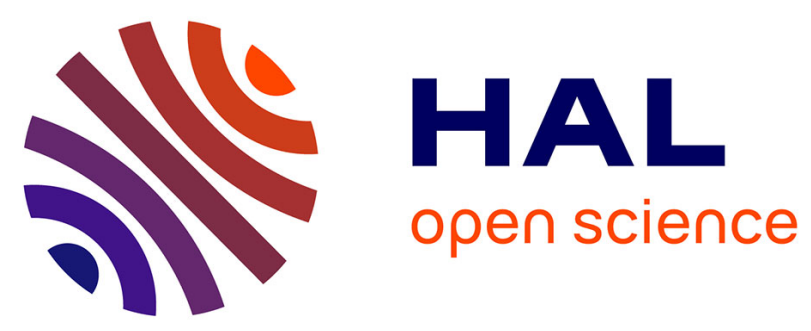

\title{
Productivity and radiation use efficiency of lettuces grown in the partial shade of photovoltaic panels
}

Hélène Marrou, Jacques Wéry, Lydie Dufour, Christian Dupraz

\section{To cite this version:}

Hélène Marrou, Jacques Wéry, Lydie Dufour, Christian Dupraz. Productivity and radiation use efficiency of lettuces grown in the partial shade of photovoltaic panels. European Journal of Agronomy, 2013, 44, pp.54-66. 10.1016/j.eja.2012.08.003 . hal-01137075v2

\section{HAL Id: hal-01137075 \\ https://hal.science/hal-01137075v2}

Submitted on 25 Jun 2015

HAL is a multi-disciplinary open access archive for the deposit and dissemination of scientific research documents, whether they are published or not. The documents may come from teaching and research institutions in France or abroad, or from public or private research centers.
L'archive ouverte pluridisciplinaire HAL, est destinée au dépôt et à la diffusion de documents scientifiques de niveau recherche, publiés ou non, émanant des établissements d'enseignement et de recherche français ou étrangers, des laboratoires publics ou privés. 


\title{
Productivity and radiation use efficiency of lettuces grown in the partial shade of photovoltaic panels
}

\author{
H. Marrou ${ }^{\mathrm{a}, \mathrm{b}, *}$, J. Wery $^{\mathrm{a}}$, L. Dufour ${ }^{\mathrm{a}}$, C. Dupraz ${ }^{\mathrm{a}}$ \\ a INRA, UMR System, 2, Place Viala, 34060 Montpellier Cedex, France \\ b Sun'R SAS, 7 rue de Clichy, 75009 Paris, France
}

\section{A R T I C L E I N F O}

\section{Article history}

Received 18 April 2012

Received in revised form 3 August 2012

Accepted 5 August 2012

\section{Keywords:}

Shade

Radiation Interception Efficiency

Radiation Conversion Efficiency

Leaf area

Lettuce

Agrivoltaic system

\begin{abstract}
A B S T R A C T
Combining photovoltaic panels (PVPs) and crops on the same land unit were recently proposed as an alternative to the conversion of cropland into photovoltaic plants. This could alleviate the increasing competition for land between food and energy production. In such agrivoltaic systems, an upper layer of PVPs partially shades crops at ground level. The aim of this work was to (i) assess the effect on crop yield of two PVPs densities, resulting in two shade levels equal to $50 \%$ and $70 \%$ of the incoming radiation and (ii) identify morphological and physiological determinants of the plant response to shade. Experiments were conducted on four varieties of lettuces (two crisphead lettuces and two cutting lettuces), during two seasons. In all cases, the relative lettuce yield at harvest was equal or higher than the available relative radiation. Lettuce yield was maintained through an improved Radiation Interception Efficiency (RIE) in the shade, while Radiation Conversion Efficiency (RCE) did not change significantly. Enhanced RIE was explained by (i) an increase in the total leaf area per plant, despite a decrease in the number of leaves and (ii) a different distribution of leaf area among the pool of leaves, the maximal size of leaves increasing in the shade. Our result provides a framework for the selection of adapted varieties according to their morphological traits and physiological responses to PVP shade, in order to optimize agrivoltaic systems.

(c) 2012 Elsevier B.V. All rights reserved.
\end{abstract}

\section{Introduction}

A consensus has emerged on the emergency to find alternative energies from renewable sources, in order to satisfy an increasing demand for energy (Escobar et al., 2009). Today, biofuels are claimed to be a promising substitute to fossil fuel (Hoogwijk et al., 2003). However, growing biomass crops on arable land raises deep concerns about food security (Pimentel et al., 2009; Tilman et al., 2009; Walker, 2009). For example, 5.9\% of arable lands in South America were occupied in 2007 with energetic crops (Rathmann et al., 2007). In Southern Europe, the development of huge groundmounted solar power plants makes local farmers protest, and alarms authorities (Nonhebel, 2005).

To conciliate these two competing uses of land, i.e. to supply the planet with both energy and food, agrivoltaic systems were recently proposed (Dupraz et al., 2010). They combine photovoltaic panels (PVPs) and food crops on the same land unit and at the same time. The first agrivoltaic array (AVA) in France was built in 2010, on a simple design as proposed long time ago by Goaetzberger and

\footnotetext{
* Corresponding author at: INRA, UMR System, 2, Place Viala, 34060 Montpellier Cedex, France. Tel.: +33499612684.

E-mail address: marrou@supagro.inra.fr (H. Marrou).
}

Zastrow (1982). Photovoltaic panels (PVPs) were settled with a clearance that allows mechanical cultivation below. Therefore, the layer of crop at ground level is partially and intermittently shaded by the cover of PVPs.

Originally, any kind of crop can be considered for cultivation in AVA systems but priority was given to horticultural productions as alley cropping is more compatible with the geometrical constraints resulting from the supporting structure. The small size of mechanical engines used in vegetable production also motivated this choice. Among the major vegetable productions in Southern Europe, lettuce was a priori particularly adequate for these pioneer systems. It can be planted at any season of the year, both in open fields and in greenhouses or shade houses (Thicoïpé, 1997), and can therefore be considered as adapted to a wide range of radiative environments.

The key point for optimizing AVA systems is to manage the limiting resource, i.e. light, so that the crop can make the best profit from the reduced light available below the solar panels. Optimization can be achieved in two manners. Firstly, playing with the density of PVPs, it is possible to modulate the degree of shading applied to the crop. Secondly, a better knowledge of the response of crop to light would lead to identify (i) light patterns that crop can manage with, (ii) functional traits to be selected.

Shade has been shown to affect crop yield by slowing down growth (Cantagallo et al., 2004; Worku et al., 2004) and reducing 


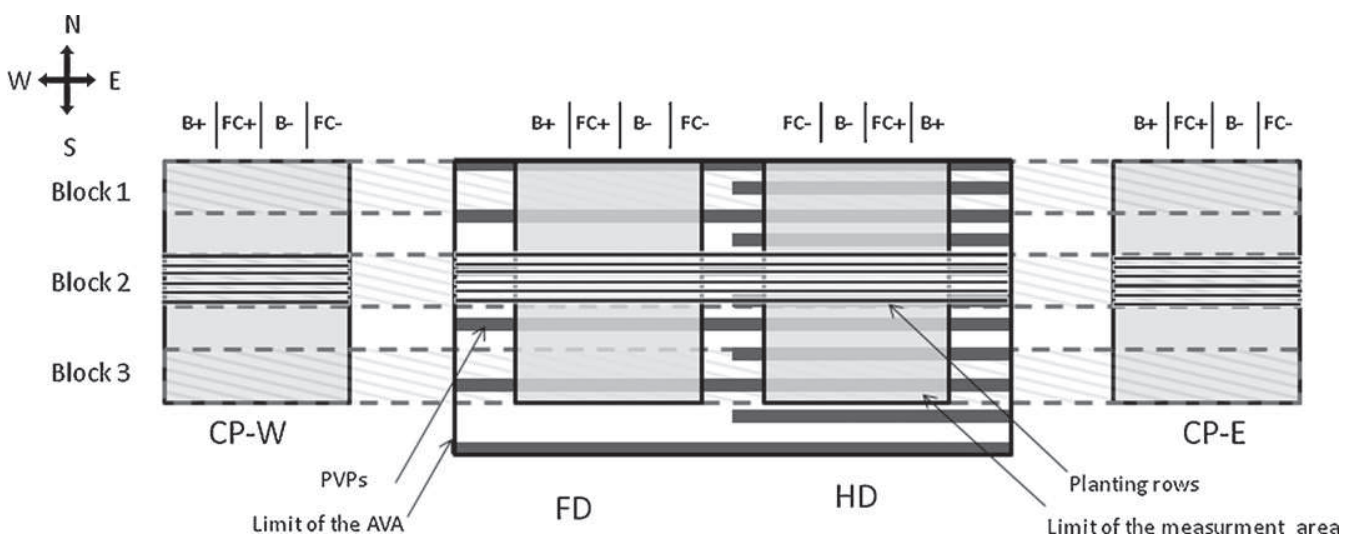

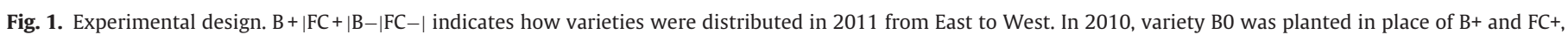
while FC+ was planted in place of B-and FC-. FD, Full Density plot; HD, Half Density plot; CP-E, East Control plot; and CP-W, West Control plots.

total biomass production at maturity (Dapoigny et al., 2000; Kitaya et al., 1998; Wacquant et al., 1995). Shade also affects leaf area and leaf characteristics such as the leaf weight to area ratio (Bensink, 1971). Similar changes were observed on pasture when intermittent shading is caused by a tree and shrub layer (Peri et al., 2007). Yield variations have also been explained by a modification of the radiation use efficiency (Dapoigny et al., 2000; Rizzalli et al., 2002).

In this study, we aim at understanding biomass production, light interception and light conversion into biomass in the specific shaded conditions created by PVPs.

\section{Materials and methods}

\subsection{Experimental agrivoltaic array (AVA)}

Experiments were conducted on the prototype of agrivoltaic system described in Dupraz et al. (2010) in Montpellier, France $\left(43^{\circ} 6^{\prime} \mathrm{N}, 3.8^{\prime} \mathrm{E}\right)$. In this AVA, PVPs were arranged in East-West orientated, $4 \mathrm{~m}$ above ground. These strips were $0.8 \mathrm{~m}$ wide and inclined southward with a tilt angle of $25^{\circ}$. The prototype was divided into 2 subsystems that differed by the distance between two successive rows of solar panels: $1.6 \mathrm{~m}$ in the "Full Density" (FD) plot and $3.2 \mathrm{~m}$ in the "Half Density" plot (HD). Inside each sub-system, the measurement area was far enough from the borders of the AVA so that they can be considered homogenous.

Two $200 \mathrm{~m}^{2}$ control plots were set up $10 \mathrm{~m}$ apart from the AVA, on the eastern (CP-E) and western (CP-W) sides. Control plots were far enough from the prototype so as not to be shaded, but close enough to be on similar soil (27\% clay, $40 \%$ silts and more than $1 \mathrm{~m}$ depth). For each variable measured on the field, the average of data collected both in CP-E and in CP-W was used as the full sun reference. Due to the large size of any agrivoltaic system required to avoid unwanted border effects (shade projections on control plots, and sun penetration from the side under shaded plots), designing replications would have involved a huge land area (several hectares) and a very costly investment ( $>1$ million euros). This was not possible at this early stage of the prototype development. We however designed the system with two important features for the statistical validity of the experiment: (1) the shaded treatments were large enough to investigate spatial heterogeneity under the panels; and (2) shaded treatments were surrounded by several full sun control plots that allowed us to control soil and crop management heterogeneity. Besides, the homogeneity of soil properties, likely to be high in this deep loamy soil had been checked in the same area formerly (Ruelle, 1995, PhD thesis). The experimental field had been uniformly cropped with cereals and no tillage since then. Soil hygrometry in the $0-30 \mathrm{~cm}$ first layer was evaluated by gravimetry on 28 soil samples taken evenly over the total area of the experimental field before the first planting, in 2010. The variation coefficient of soil hygrometry was equal to $9.4 \%$ only. In addition, the experiment was conducted under non-limiting conditions for water and nitrogen to limit the effect of soil factors on crop. A monitoring of the soil water status was performed weekly in all plots (tensiometers and neutron probe measurements) to control the uniformity of the irrigation scheme. A variance analysis of lettuce yield at final harvest was performed on the 2 full sun plots located on the Eastern (CP-E) and Western (CP-W) sides of the AVA. Each plot was divided into three blocks in the North-South direction. Variance analysis showed that there was neither significant block nor plot effects. These preliminary controls entitle us to consider that the effects of non-monitored environmental factors - if any were negligible.

\subsection{Crop management}

Two lettuce varieties (B0 and FC+) were planted on July 22, 2010. The variety FC+ was planted again on March 23, 2011 along with three other varieties: B+, B- and FC-. Varieties B0, B+ and B-belong to the subspecies "Batavia" L. sativa acephala sp., and correspond to varieties "Tourbillon" (B0), "Model" (B+), and "Emocion"(B-). Varieties FC+ and FC- belong to the subspecies "Feuille de Chêne" (L. sativa. acephala sp.) and correspond to varieties "Kiribati" (FC+) and "Bassoon" (FC-).

Seedlings were planted under the AVA in blocks of rows with East to West orientation. Each block was composed of seven rows in 2010 and six rows in 2011 (Fig. 1). The distance between two planting rows was $33 \mathrm{~cm}$ and the distance between two lettuces on a row was $27 \mathrm{~cm}$.

Irrigation was provided by sprinklers (2010) or drip lines (2011) and nitrogen fertilizers were applied immediately before planting and during the cycle. Water and nitrogen status were monitored weekly by tensiometers and chlorophyllmeter readings (SPAD-502, Konica Minolta Inc., Japan) in order to ensure that lettuces were not submitted to water or nitrogen stress in any treatments.

\subsection{Microclimate monitoring}

Available radiation at crop canopy level was measured hourly in each treatment with pyranometers (Quantum sensors - Skye instruments Ltd., UK) or photosynthetically active radiation (PAR) 
sensors connected to data loggers (CR1000 - Campbell Scientific Inc., USA). Sensors were installed just above lettuce heads, both in the FD and in the HD plots along North-South transects between two panel strips. In 2010, 3 pyranometers, regularly spaced were used per transect in FD and in HD. In 2011, one sensor was set above each planting rank in a transect. PAR sensors and pyranometers were considered to be equivalent after we checked it in a complementary experiment during which several pyranometers and PAR sensors were placed together at the same locations, in the full sun, and in the shaded treatments. By comparing the hourly records of the PAR sensors and the related pyranometers, we checked that PAR/Global ratio was fairly closed to 0.48 both in the shade and in the full sun, at any time of the day (data not shown).

Hemispherical photographs were also taken above each row of lettuces. Decadal percentages of available total radiation were calculated from the photographs with the Gap Light Analyser software (Frazer et al., 1999) for the time period when sensors were in the field.

Mean daily air temperature and relative humidity $2 \mathrm{~m}$ above ground as well as crop temperature were checked to be uniform between the treatments (data not shown). Air temperature and air relative humidity were recorded hourly (HMP35 and HMP45 probes, Campbell Scientific Inc., USA). In 2011, crop temperatures were measured hourly by thermocouples (Copper-Constantan thermocouples) directly inserted into the plants, close to the plant axis, between the larger lettuce leaves.

\subsection{Simulation of radiation available to plants}

A radiative model was written and implemented in $R$ (http://cran.r-project.org/) using a ray-tracing algorithm on a 3D scene. The model used daily global radiation measured on the experimental site as an entry, as well as the latitude of the site. Global radiation is allocated to sectors of the sky according to a Standard Overcast Sky distribution. The scene represents the panel strips with the same size and orientation as in the field prototype. However, HD and FD sub-systems are modeled separately and the supporting structure is not taken into account by the model. Daily available radiation at a given point of the stage is calculated by integrating the interception of rays launched toward this point from each sky sectors. Calculations are iterated with a daily time step for each position on the scene with a spatial grid of $10 \mathrm{~cm} \times 10 \mathrm{~cm}$. The output radiation is expressed as Global Radiation or PAR - depending on the specification of the user - using a PAR/Global ratio equal to 0.48 . Model algorithms are described in Appendix A. The radiation model was validated in 2010 by comparing model outputs to GLA computations and pyranometers records.

\subsection{Lettuces growth measurements}

Lettuces were sampled for destructive measurements of biomass at three dates in 2010 (21,34, and 47 days after planting DAP), and in 2011 (23, 44, and 63 DAP). The last harvest corresponds to the maturity stage for commercial selling.

Three to five (depending on the sampling date) lettuces of each variety were picked randomly in CP-E and CP-W at each sampling date. In FD and HD, three to five lettuces were picked in each planting row (discarding external rows) in order to get a stratified sample that take into account the radiative spatial heterogeneity under the AVA. Total aerial dry matter and leaf number were measured for each lettuce. The length and the width of each leaves were measured for at least one lettuce per row and per treatment. In 2011, leaves were stripped off five by five, for each sampled lettuce. Each group of leaves was dried up separately after measuring the length and width of one leaf, in order to calculate specific leaf area of each group of five leaves. On a subsample of lettuces, a direct measurement of each leaf area was obtained by horizontal photography and image treatment (ImageJ, MD, USA) to check the relation between length, width and exact area of lettuce leaves. As suggested by Gay (2002), a linear regression was fitted between exact leaf area and width $\times$ length. A single allometric relation was fitted for all varieties together with a relative RMSE of $3.2 \%$.

\subsection{Intercepted $P A R$}

Lettuce CR was assessed periodically. In 2011, three lettuces per variety and per treatment were monitored with vertical photographs at a weekly interval. After image processing (ImageJ, MD, USA) the dynamic of cover rate evolution with time was obtained for each lettuce. In 2010, vertical photographs were taken only once, on 18th August but the diameter of the plants was measured at three dates in the field or on sampled plants. A linear relation $\left(R^{2}=0.83\right)$ was found between CR estimated from the photographs on one hand and from the diameters measurements in the same day, on the other hand. The corresponding linear transformation was applied to all the CR estimates calculated from the diameter measurements in 2010, to get a homogenous and consistent dataset across the two years. In 2011, a direct measurement of intercepted PAR was realized in the field every two weeks on part of the marked lettuces. To do so, a radiation measurement was taken above each lettuce head, at solar noon, by use of a portable PAR sensor (JYP 1000 - SDEC, France). Immediately after that, nine other measurements were taken at ground levels distributed regularly on a $27 \mathrm{~cm} \times 33 \mathrm{~cm}$ square around the same lettuce. Intercepted PAR was calculated as the ratio between mean ground level measurement and the above lettuce canopy measurement.

\subsection{Calculation of radiation use}

\subsubsection{General framework}

Biomass accumulation was analyzed through a light centered approach. According to Monteith (1972, 1977), biomass production is the result of two successive processes: radiation interception of incident PAR $\left(\mathrm{PAR}_{\text {inc }}\right)$ and the conversion of intercepted radiation $\left(\mathrm{PAR}_{\text {int }}\right)$ into dry matter. The efficiencies of these processes are named Radiation Interception Efficiency (RIE) and Radiation Conversion Efficiency (RCE) respectively. In the case of AVA, transmission of sun radiation $\left(\mathrm{PAR}_{0}\right)$ through solar panels results into $\mathrm{PAR}_{\mathrm{inc}}$ and should be added as the first step of the process. Radiation Transmission Efficiency (RTE) depends on PVPs arrangement and density.

Hence, accumulation of dry matter (DM) is given by Eq. (1).

$\mathrm{DM}=\mathrm{PAR}_{0} \times \mathrm{RTE} \times \mathrm{RIE} \times \mathrm{RCE}$

To compare FD and HD treatments to full sun, relative variables are calculated as the ratio between the values in shaded treatments and in the full sun control. Considering that $\mathrm{PAR}_{0}$ is identical in full sun and under PVPs and that RTE in full sun equals one leads to Eq. (2), in the case of FD. The same relation can be written for HD. Relative variables are noted with the suffix letter $\mathbf{r}$.

$\mathrm{rDM}_{\mathrm{FD}}=\mathrm{RTE}_{\mathrm{FD}} \times \mathrm{rRIE}_{\mathrm{FD}} \times \mathrm{rRCE}_{\mathrm{FD}}$

Applying logarithmic transformation, log-relative dry matter ( $\mathscr{}$ DM) in the shade can be written as the sum of the contributions of light transmission, interception and conversion (Eq. (3)). This equation refers to FD and a similar equation can be written for HD. While

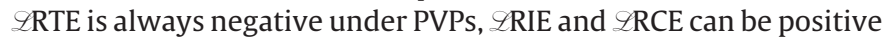
or negative, depending on whether interception and conversion efficiencies increase or decrease in the PVP shade, compared to the full sun control.

$\mathscr{D D M} \mathrm{FD}=\mathscr{R} \mathrm{RTE}_{\mathrm{FD}}+\mathscr{R} \mathrm{RIE}_{\mathrm{FD}}+\mathscr{2} \mathrm{RCE}_{\mathrm{FD}}$ 
Table 1

Estimated parameters for a logistical adjustment of the cover rate as a function of thermal time (Eq. (8)).

\begin{tabular}{|c|c|c|c|c|c|c|}
\hline & \multicolumn{2}{|l|}{2011} & \multicolumn{4}{|l|}{2010} \\
\hline & \multirow[t]{2}{*}{ Shade (FD, HD) } & \multirow[t]{2}{*}{ Full sun } & \multicolumn{2}{|c|}{ Shade (FD, HD) } & \multicolumn{2}{|l|}{ Full sun } \\
\hline & & & B0 & $\mathrm{FC}+$ & B0 & $\mathrm{FC}+$ \\
\hline$A$ & 0.94 & 0.63 & 0.737 & 0.849 & 0.708 & 0.841 \\
\hline$\lambda$ & & & 0.010 & 0.013 & 0.010 & 0.012 \\
\hline$\mu$ & & & 557.0 & 544.5 & 544.8 & 567.6 \\
\hline
\end{tabular}

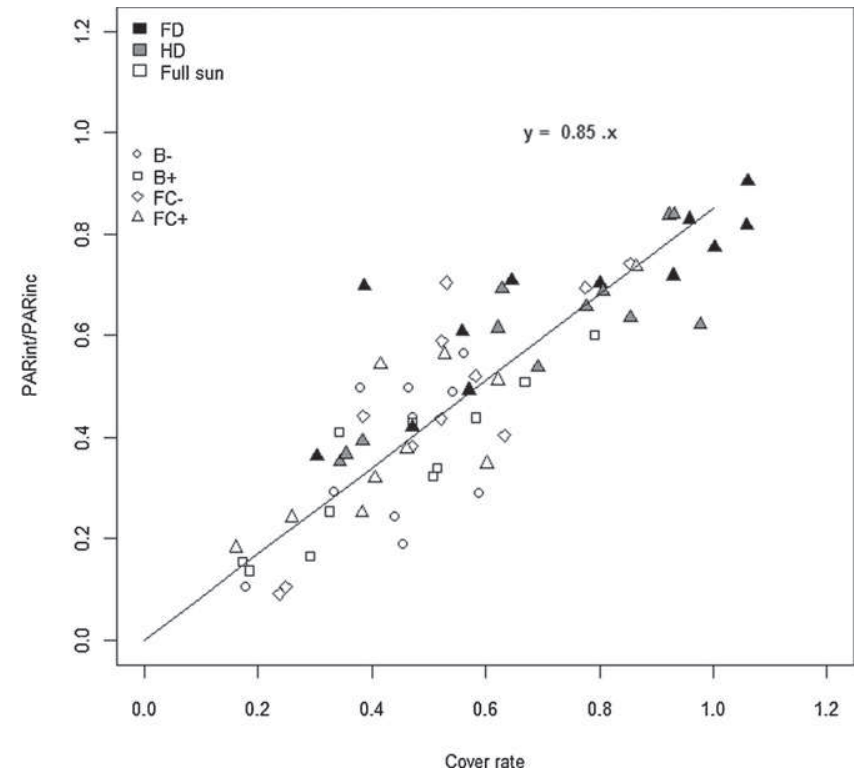

Fig. 2. Relation between the measured fraction of intercepted PAR at solar noon and cover rate estimated from photographs, in 2011. o, $\square, \diamond, \Delta$ stand for varieties $\mathrm{B}+, \mathrm{B}-, \mathrm{FC}+, \mathrm{FC}-$, respectively. Closed black symbols, closed gray symbols, and open symbols represent plant in the FD, HD, and full sun plots, respectively.

From field data and radiation simulations, we calculated $\mathscr{R}$ RE, $\mathscr{R} I E$, and $\mathscr{R} C E$, for a given time period (e.g. the total cropping season), and a given area (e.g. the total measurement area of HD, FD and CP plots).

\subsubsection{Radiation transmission efficiency}

Over the cropping season, RTE was calculated according to the following formula:

$\mathrm{RTE}=\frac{\sum_{t=\text { planting }}^{t=\text { harvest }}\left(\mathrm{PAR}_{\text {inc }, t}\right)}{\sum_{t=\text { planting }}^{t=\text { harvest }}\left(\mathrm{PAR}_{0, t}\right)}$

Standard error of RTE was calculated by propagation of the standard error on PAR $_{\text {inc }}$ simulated for each planting row in FD and HD plots.

\subsubsection{Radiation Interception Efficiency}

Over the cropping season, RIE is calculated according to Eq. (5).

$\mathrm{RIE}=\frac{\sum_{t=\text { planting }}^{t=\text { harvest }} \text { PAR }_{\text {int }, t}}{\sum_{t=\text { planting }}^{t=\text { harvest }} \text { PAR }_{\text {inc }, t}}$

In the case of lettuce, the daily percentage of incident PAR intercepted $\left(\mathrm{PAR}_{\text {int }, t} / \mathrm{PAR}_{\text {inc }, t}\right)$ can be assessed as a linear transformation of the crop cover rate (CR), or $\mathrm{CR}^{n}$ (De Tourdonnet, 1998; Gay, 2002; Hunt et al., 1984; Tei et al., 1996). We fitted our data with a unique linear adjustment (Fig. 2) with forced to 0 origin, between $\mathrm{PAR}_{\text {int }, t} / \mathrm{PAR}_{\text {inc }, t}$ and CR, yielding a RMSE of 0.107 (Eq. (7)). Unicity of the adjustment amongst varieties and treatments was checked with tests of the maximum of likelihood performed with the $\mathrm{R}$ software (Eqs. (6) and (7)). The value of the coefficient (0.85) is in the same range as those previously reported (see above) and is consistent with a crop reflectance of 5-15\%.

$\frac{\mathrm{PAR}_{\text {int }, t}}{\mathrm{PAR}_{\text {inc }, t}}=0.85 \times \mathrm{CR}_{t}$

Then,

$\mathrm{RIE}=\frac{\sum_{t=\text { planting }}^{t=\text { harvest }}\left(0.85 \times \mathrm{CR}_{t} \times \mathrm{PAR}_{\text {inc }, t}\right)}{\sum_{t=\text { planting }}^{t=\text { harvest }} \mathrm{PAR}_{\text {inc }, t}}$

$\mathrm{CR}_{\mathrm{t}}$ was fitted as a function of thermal time with Van Holsteijn equation (De Tourdonnet, 1998; Gay, 2002; Holsteijn, 1980) using measurements of cover rate collected in the field in 2010 and 2011 (Eq. (8)).

$\mathrm{CR}_{t}=\frac{A}{1+e^{\left(-\lambda \times\left(\mathrm{TT}_{t}-\mu\right)\right)}}$

where TT is the thermal time with a base temperature of $3.5^{\circ} \mathrm{C}$.

Thermal time was calculated from air temperature measurement above control plots (CPs): indeed no significant difference in cumulated thermal time was measured between FD, HD and the control plots, whatever reference temperature is used (crop or air temperature) (not shown). Data from 2010 and 2011 were processed separately as CR dynamic was very different in the two years, due to seasonal effect. Parameters $A, \lambda$, and $\mu$ (Table 1 ) were adjusted with the gnls procedure of $\mathrm{R}$ (http://cran.r-project.org/). Tests of the maximal likelihood showed that, for both 2010 and 2011 , a single adjustment can be used to predict $\mathrm{CR}_{t}$ for treatments FD and HD together, whereas a different set of parameters must be fitted for treatment CP (Fig. 2). Concerning the factor variety, it was possible to fit a single model for all varieties in 2011, but not in 2010. Standard errors of estimated cover rates were calculated for every day according to Seber and Wild (Pellegrino et al., 2006; Seber and Wild, 2003) (Fig. 3).

Uncertainties related to model adjustments for $\mathrm{CR}_{t}$ and $\mathrm{PAR}_{\text {int }}$ and spatial variability for PAR $_{\text {inc }}$ were propagated through the calculation to get the standard error of RIE and RCE. DM and CR were assumed to be uncorrelated as the corresponding measurements were realized on different plants, while autocorrelation of cumulated variables (PAR) was accounted for in the calculation of uncertainties. Model error (CR as a function of TT) and measured variability were assumed to be additive. Uncertainties were propagated through non-linear transformations by derivation $(\mathrm{Ku}$, 1966).

Student tests were performed on mean estimates of RIE for each variety, using intra-treatment variability as variance estimators and $(n-1)$ degrees of freedom, where $n$ is the minimal sample size for all the measured or simulated variables involved in the calculation $(n \geq 3)$. 
(2a) Summer 2010

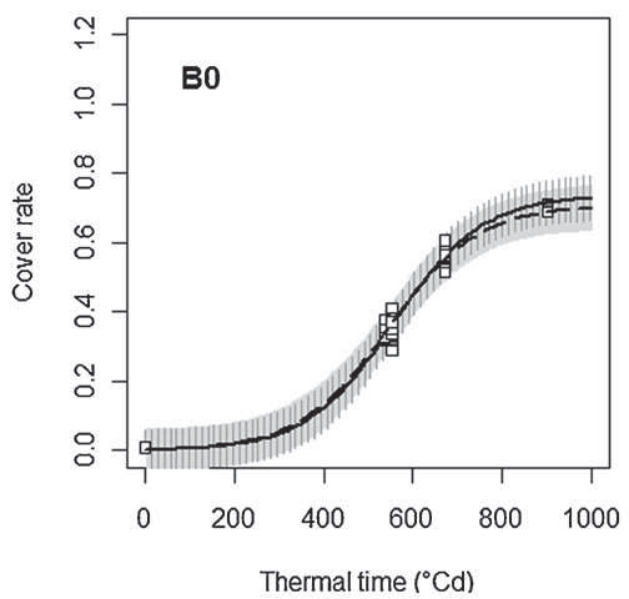

(2b) Spring 2011

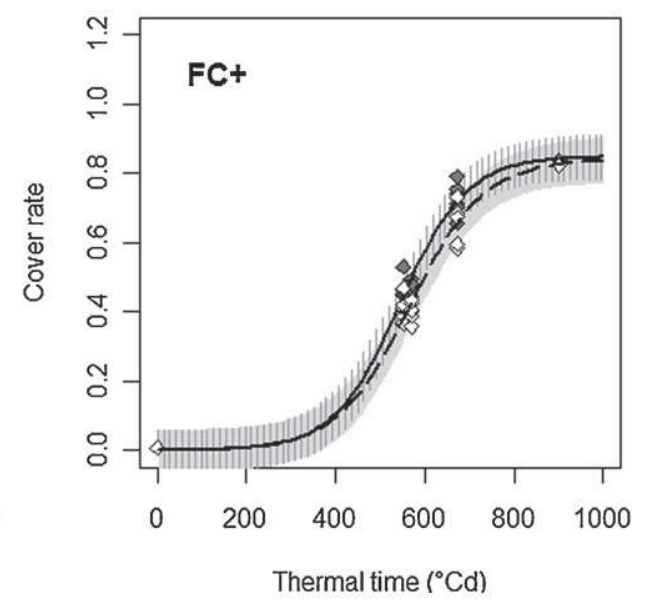

Thermal time $\left({ }^{\circ} \mathrm{Cd}\right)$

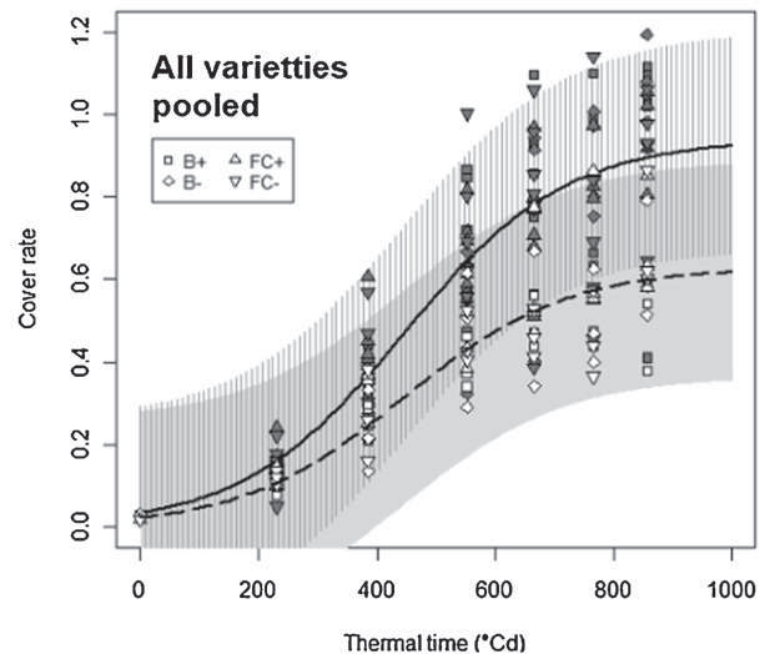

Shade $-\infty$ Full Sun

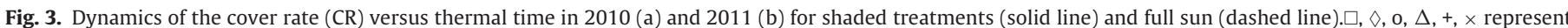

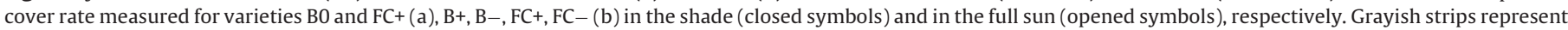
$95 \%$ confidence interval of the adjustment.

\subsubsection{Radiation Conversion Efficiency}

RCE was calculated according to Eq. (9), over the cropping season.

$\mathrm{RCE}=\frac{\mathrm{D} \times \mathrm{DM}_{t=\text { harvest }}}{\sum_{t=\text { planting }}^{t=\text { harvest }} \mathrm{PAR}_{\mathrm{int}, t}}$

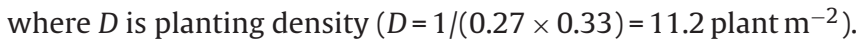

Dry matter of lettuce was supposed to be negligible at planting date (four leaves stage). Standard error of RCE was obtained by propagating standard error of DM measured on lettuce samples at harvest and standard error of $\mathrm{PAR}_{\text {int }}$ calculated as explained above.

\section{Results}

\subsection{Radiation transmitted below an AVA}

\subsubsection{Validation of the radiative model}

We compared model outputs to field data by calculating the root mean square error (RMSE) and $R^{2}$ coefficient between simulations and field data (pyranometer records and hemispherical photographs). The analysis was repeated for different levels of spatial and temporal integration from individual lettuce on a day to the total area of each treatment plot over the whole season, to evaluate the sensitivity of the model to the variability in time and in space within each shaded treatments (Table 2). The correlation between field data and the radiation model increased with the level of integration with time and space. Except for the coarsest integration level using GLA computations, $R^{2}$ was above 0.70 and the relative RMSE was below $18 \%$. The radiation model was therefore considered as a fair predictor of the available radiation bellow the PVPs, with no risk of bias when comparing HD and FD treatments. Model outputs, averaged spatially and/or over time were used for further calculations.

\subsubsection{Predicted radiation under the AVA}

The relative transmitted (available at plant level) radiation (RTE, Eq. (4)) during the cropping season averaged 53\% in FD for both 2010 and 2011 (Fig. 4). It varied from 48\% to 56\% depending on the planting row, for the two years. In HD, it varied from $68 \%$ in summer 2010 to $73 \%$ in spring 2011. Variability of available light between planting rows was higher in this treatment: it ranged between $63 \%$ and $72 \%$ in 2010 and between $71 \%$ and $74 \%$ in 2011 . Besides, the hourly pattern of radiation varied from one row to another and differed between days for the same row (data not shown). In the following steps, we therefore use the spatial average of PAR $_{\text {inc }}$, which integrate this variability, in order to characterize the FD and HD treatments. 
Table 2

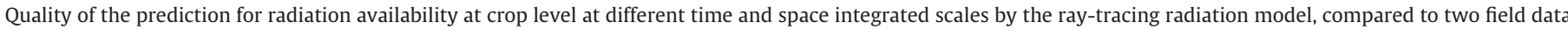
sources: hemispherical photographs processed with GLA software and pyranometer records.

\begin{tabular}{|c|c|c|c|c|c|}
\hline \multirow[t]{2}{*}{ Space integration } & \multirow[t]{2}{*}{ Time integration } & \multicolumn{2}{|l|}{ GLA } & \multicolumn{2}{|c|}{ Pyranometers } \\
\hline & & $\overline{R^{2}}$ & CV (RMSE) \% & $\overline{R^{2}}$ & RRMSE \% \\
\hline 1 sensor location & 1 day & & & 0.80 & 22.0 \\
\hline Total plot area & 1 day & & & 0.92 & 11.2 \\
\hline 1 sensor location & 10 days & 0.56 & 27.3 & 0.80 & 17.8 \\
\hline Total plot area & 10 days & 0.89 & 11.4 & 0.91 & 9.5 \\
\hline 1 sensor location & 76 days & & & 0.93 & 6.6 \\
\hline
\end{tabular}
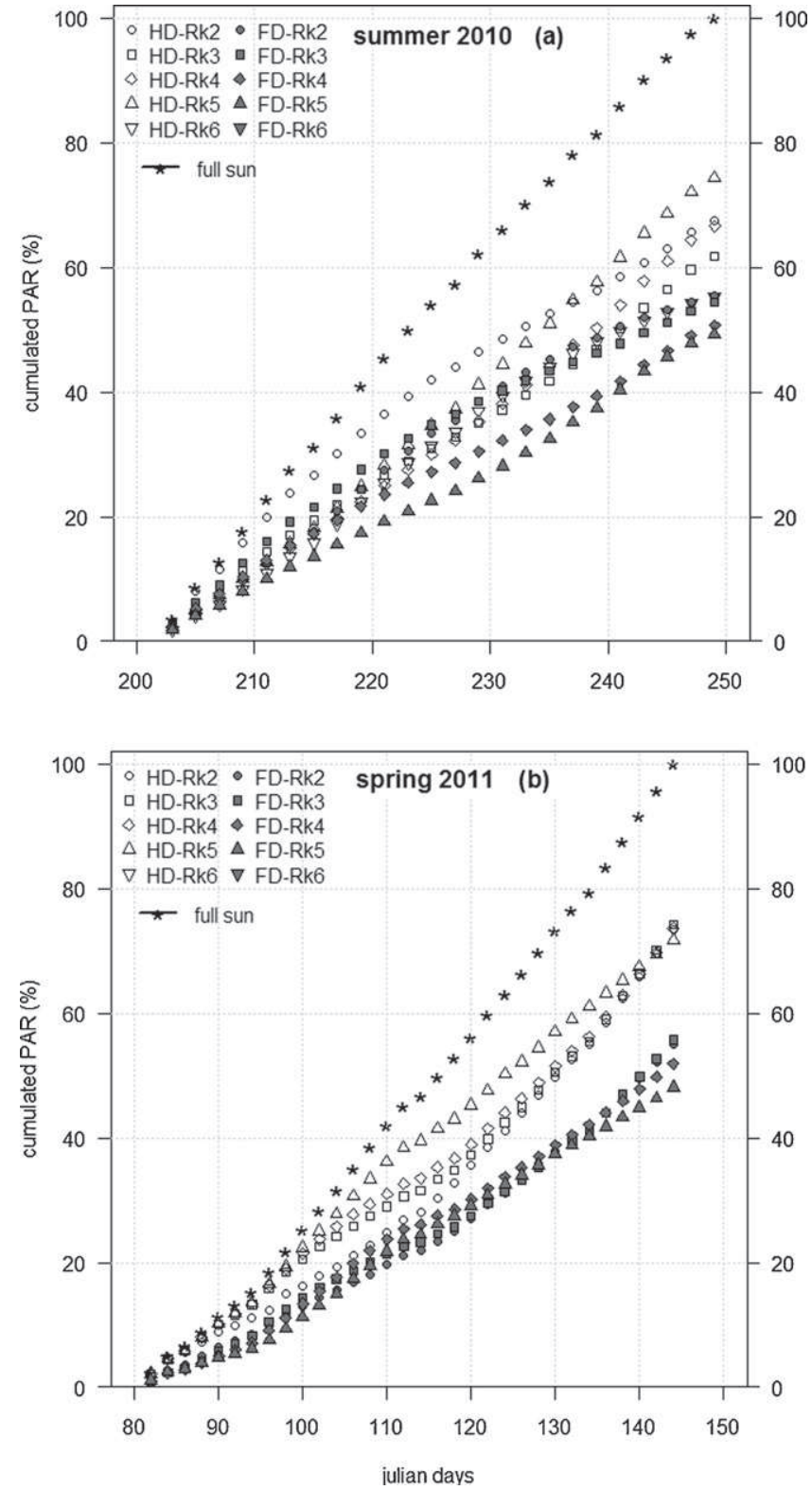

Fig. 4. Cumulated incident PAR in the full sun (measurements) and for each planting row position (Rk2-Rk6 in 2010 and Rk2-Rk5 in 2011) in the FD and HD treatments (simulations), during the two cropping seasons (summer 2010 and spring 2011). Incident PAR is expressed in percent of the cumulated PAR in the full sun, at the end of the cropping season.

\subsection{Lettuce yield and light use}

\subsubsection{Yield of lettuces in the shade of an AVA}

The average yield in the full sun approximately reached $25 \mathrm{~g}$ of dry matter per plant in the two seasons. Fresh weight in the full

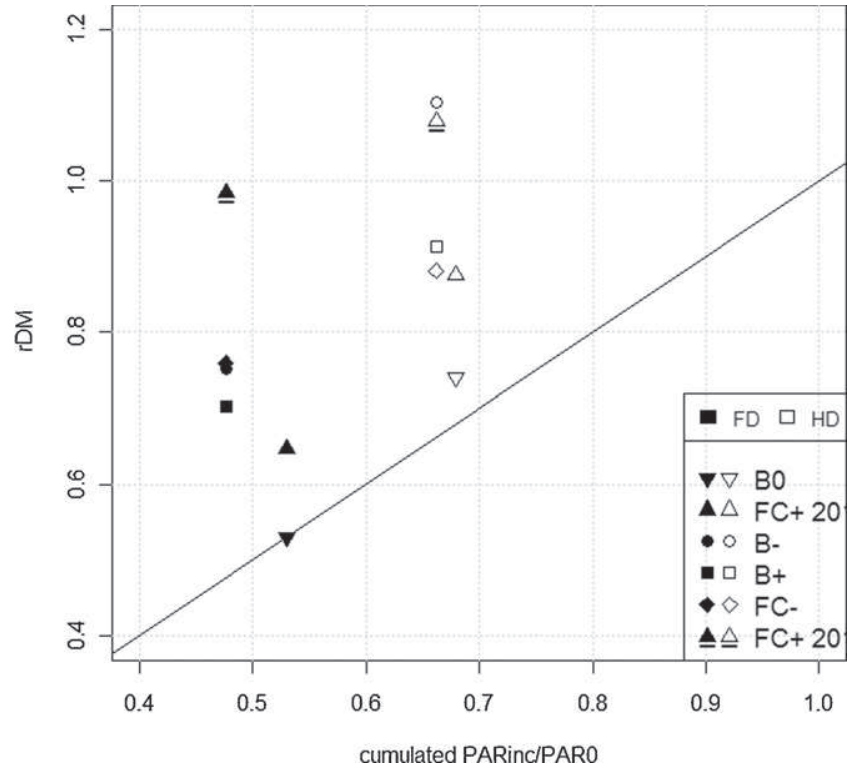

Fig. 5. Relative Dry matter of lettuces plotted versus relative available light (PARinc/PAR0) at harvesting date (47 DAP in 2010, and 63 DAP in 2011). Filled symbols correspond to FD treatment, while open symbols represent HD treatments.

sun was $561 \mathrm{~g}$ per plant in summer 2010 and $312 \mathrm{~g}$ in 2011, for all varieties. According to Thicoïpé (1997) minimal fresh weight for lettuce commercialization in France is $280 \mathrm{~g}$ per plant in winter and $400 \mathrm{~g}$ in summer. This is a further confirmation that plants were grown close to their potential in the full sun and that light was the main limiting factor in the FD and HD plots, as targeted with our monitoring and management of water and nitrogen status of the crop (see Section 2.2).

In 2010, yield was reduced significantly to $58 \%$ of control (all varieties together), when plants were submitted to heavy shading (FD). In HD, yields were at $81 \%$ of the control yield for the same year. In 2011, yield reductions were lower: they equaled $79 \%$ of full sun in FD and 99\% in HD. This indicates that, at least in the spring planting conditions of 2011, yield was hardly affected when the shade was moderate (i.e. in the HD design). In 2011, for varieties FC+ and B-, yield in HD were even above that of the full sun. Moreover biomass reduction was less than the available light reduction, for every sampling date with the exception of B0 in 2010 (Fig. 5). This shows the capacity of lettuce to produce biomass more efficiently when the light resource is reduced.

The spatial heterogeneity of light at crop level in FD and HD (see Section 3.1.2) was not translated in lettuce yield. Differences in yield between planting rows within the same treatment were significant but negligible compared to differences between treatments (test of maximum likelihood).

The comparison between varieties highlighted differences in the tolerance to shade: in 2011 varieties FC+ and B- appeared to be less affected by shade than the two others. In 2010, variety FC+ gave better results than $\mathrm{B} 0$. Seasonal effect interacted with the shade 
FD

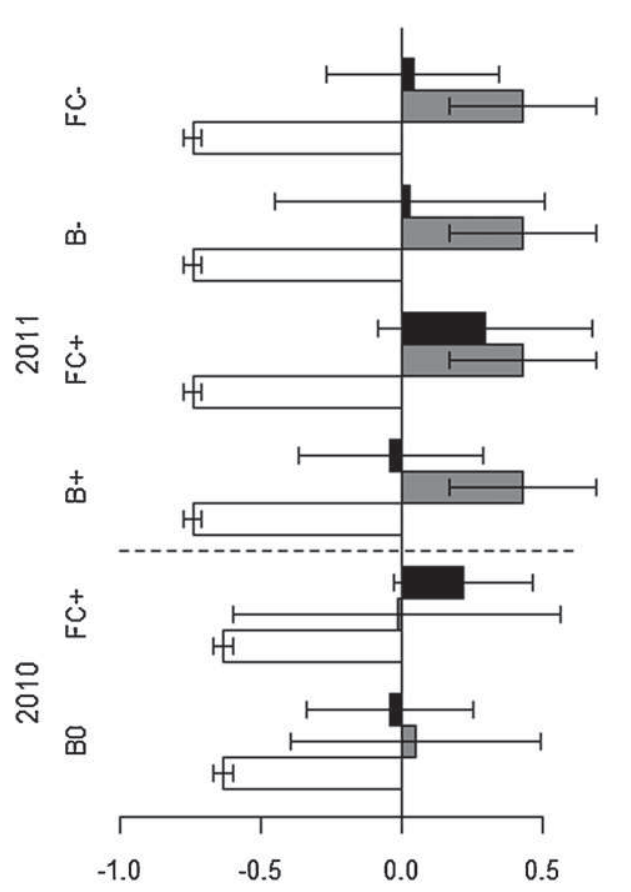

HD

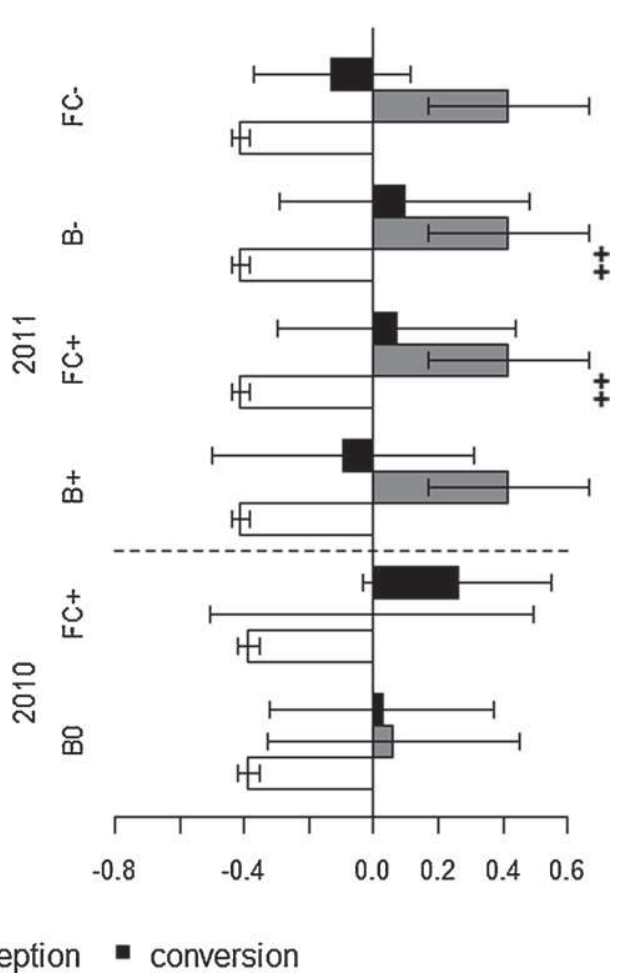

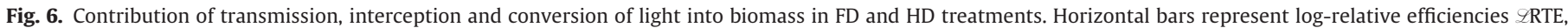
$\mathscr{R} I E$, and $\mathscr{R}$ RE. Error bars feature standard deviation of respective efficiencies. '++' indicates varieties for which dry matter in HD exceeded dry matter in the full sun.

treatment, variety FC+ having a lower yield in the shade in summer 2010 but a higher yield in the shade in 2011.

\subsubsection{RIE and RCE in the PVPs shade}

The relative light availability (RTE) was similar in 2010 and 2011 (Fig. 6). In 2010, RIE was not significantly different in the PVPs shade (neither FD nor HD), compared to the full sun, according to a Student's test. In 2011, it was significantly increased in the shade ( $p$-value $=0.0036$ in FD and 0.0023 in HD, Student's test), and was higher in FD (0.460) than in HD (0.454). RIE is proportional to CR (Eq. (6)), which was significantly higher in the shade (0.94) than in the full sun (0.63) at final harvest (Fig. 2). We could not show significant differences in RCE under shade for any of the varieties. However, for variety FC+, which is the most productive, RCE tended to increase in the shade both in 2010 and 2011.

\subsection{Yield components of lettuce in the PVPs shade}

\subsubsection{Number of leaves}

In 2010, the number of leaves (longer than $1 \mathrm{~cm}$ ) was significantly reduced in the shade for each sampling date (Fig. 7). In 2011, the number of leaves was also reduced significantly in FD for each variety and every sampling date. In HD, the number of leaves was unchanged for most varieties, but it decreased significantly for variety FC- (not shown).

\subsubsection{Leaf area and thickness}

In 2011, the total leaf area increased significantly in FD, compared to $\mathrm{CP}$, for each variety, from 43 DAP to 63 DAP unlike the number of leaves (Fig. 8). In HD, leaf area tended to increase too, but change was significant only for varieties FC+ and B-, at 63 DAP. In 2010, at 47 DAP, total leaf area was smaller in the shade, but the difference was not significant.
For each variety, in 2011, the maximum of the length $\times$ width product averaged over a group of five continuous leaves (called here a crown) in a plant, was significantly higher in the shade than in full sun (Fig. 9). Therefore the higher plant leaf area in the shade observed in spring planting was the consequence of an increased size of "mature leaves" of lettuces (Fig. 8). We call "mature leaves" the group of leaves whose area overpassed $75 \%$ of the size of the biggest leaf of the plant. Mature leaves are representative of the growth potential of the plant (Bensink, 1971) and they determine the circumference of the lettuce head.

The specific leaf area (SLA = leaf area/leaf dry weight) of mature leaves was significantly higher in the shade for all varieties. As SLA has been shown to be closely related to leaf thickness (Wilson et al., 1999), we can make the hypothesis that leaf thickness has been reduced by the shade conditions created by the PVPs. On the contrary, the length/width ratio of mature leaves was not modified in the shade.

\section{Discussion}

\subsection{Contribution of RCE and RIE to the tolerance of lettuces to PVPs shade}

We found that lettuces can maintain relatively high yields under $\mathrm{PV}$, in the HD shade treatment and, for some varieties, in the FD treatment in spring growing conditions (Table 3). By use of Monteith equation adapted to AVA (Eq. (1)), we showed that tolerance to PVPs shade mainly relied on the ability of lettuces to improve their capacity to intercept light (Fig. 6). This result is consistent with Sinclair et al. (1999) and Gimenez et al. (2002). Interception was assumed to be a physical process, directly proportional to the percentage of ground cover. The relation between cover rate and percentage of interception was unchanged when plants were 
(a)

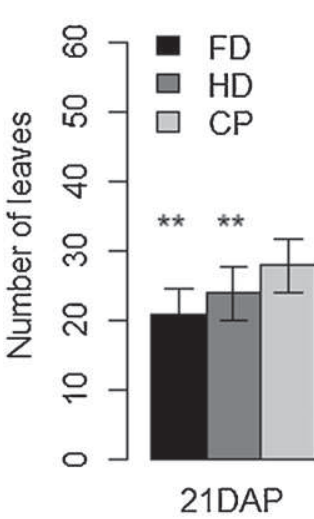

2010

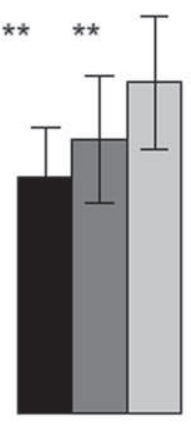

34DAP

(b)

2011
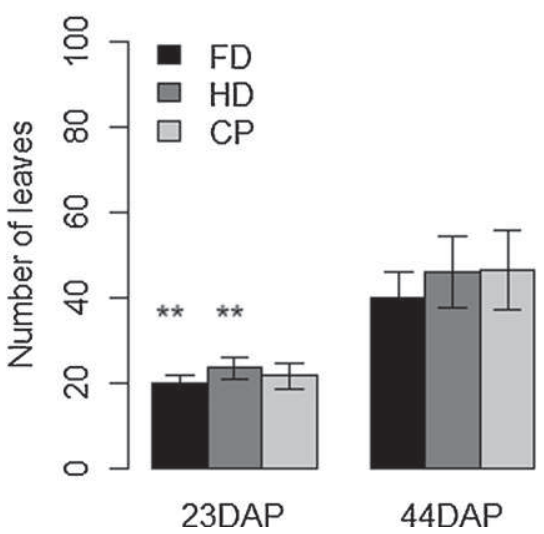

(a)

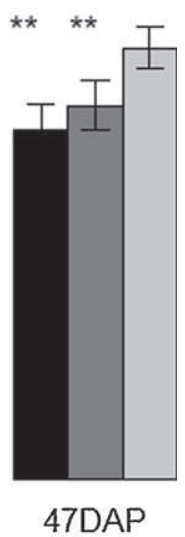

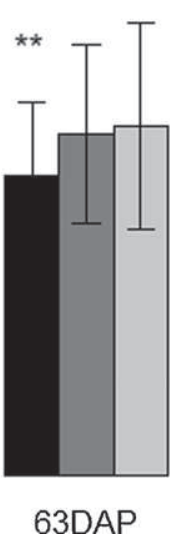

Fig. 7. Number of leaves longer than $1 \mathrm{~cm}$ per lettuce, for all varieties together at 21,34 and 47 DAP in 2010, and 23, 44 and 63 DAP in 2011. Vertical error bars feature standard deviations. FD and HD bars are marked with '**' when the number of leaves is significantly different from the CP at the same date, according to LSD test with a risk $\alpha=5 \%$.

grown in the shade. Consequently, improved RIE can be directly attributed to a better ability of the plant for a higher and more rapid soil covering under the PVPs shade. This was achieved with morphological changes contributing to (i) an increase in the total plant leaf area and (ii) an optimized leaf area arrangement to harvest light more efficiently. The various plant strategies to achieve this are summarized in Fig. 10 and analyzed below on the basis of our observations.

\subsubsection{Strategy 1: increasing total plant leaf area}

This can be obtained with an increased mean size of leaves and/or number of leaves.

We showed that the individual area of mature leaves increased whereas the number of leaves decreased significantly in the shade (FD and HD). In the full sun, CR can be predicted by allometry as a logistical function of the number of leaves (Gay, 2002). From

2010

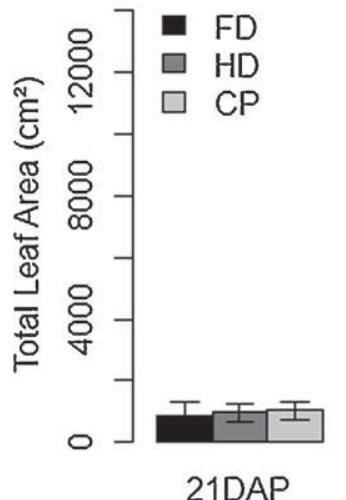

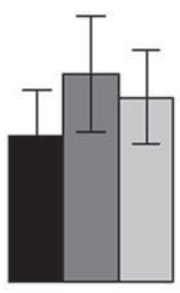

34DAP

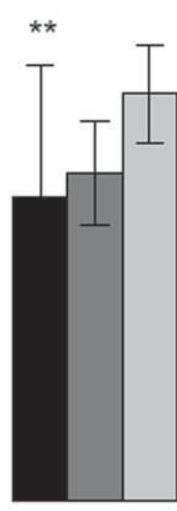

47DAP
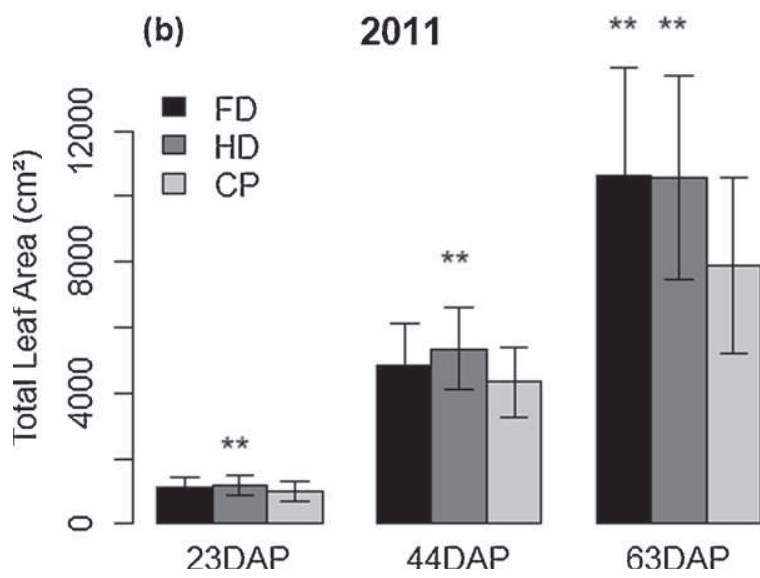

Fig. 8. Total leaf area, for all varieties together at 21, 34 and 47 DAP in 2010, and 23, 44 and 63 DAP in 2011. Total leaf area is calculated through destructive measurement as the sum of the length $\times$ width product of every leaf longer than $1 \mathrm{~cm}$. Vertical error bars feature standard deviations. FD and HD bars are marked with ${ }^{~ * * *}$ when the total foliar area is significantly different from the $\mathrm{CP}$ at the same date, according to LSD test with a risk $\alpha=5 \%$.

field data, two different models were fitted for plants in the sun, and plants in the shade. They were tested to be different with the likelihood ratio test $\left(p\right.$-value $\left.=4.7 \times 10^{-4}\right)$. This confirmed that the number of leaves cannot explain the increase of CR in the shade. However, reducing leaf number could have allowed the production of larger leaves for the same amount of carbon assimilated. Bensink (1971) showed that in the shade, leaf emission rate decreased and leaf growth duration increased, thereby resulting in longer and wider leaves. This suggests that, in the shade, carbon allocation is preferentially directed to further leaf growth instead of leaf emission (Bensink, 1971).

4.1.2. Strategy 2: better arrangement of the light harvesting area 4.1.2.1. Increasing head diameter. Ground projection of a lettuce head can be approximated as a disk the radius of which is equal

Table 3

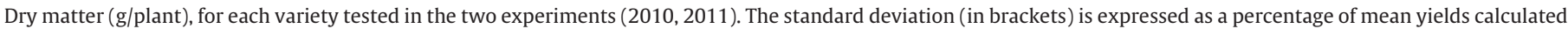
on the corresponding sample (i.e. three to five lettuces).

\begin{tabular}{|c|c|c|c|c|c|c|}
\hline & \multicolumn{2}{|c|}{2010 (Summer) } & \multicolumn{4}{|c|}{2011 (Spring) } \\
\hline & B0 & $\mathrm{FC}+$ & B- & $\mathrm{B}+$ & $\mathrm{FC}-$ & $\mathrm{FC}+$ \\
\hline FD & $13.9^{\mathrm{a}}(17 \%)$ & $16.0^{\mathrm{a}}(12 \%)$ & $17.8^{\mathrm{a}}(33 \%)$ & $18.4^{\mathrm{a}}(21 \%)$ & $18.9(23 \%)$ & $21.6(25 \%)$ \\
\hline HD & $19.4^{\mathrm{a}}(26 \%)$ & $21.7^{\mathrm{a}}(21 \%)$ & $26.1^{\mathrm{a}}(17 \%)$ & $23.9(32 \%)$ & $21.9(13 \%)$ & $23.7(24 \%)$ \\
\hline $\mathrm{CP}$ & $26.2(21 \%)$ & $24.9(16 \%)$ & $23.7(33 \%)$ & $26.2(23 \%)$ & $24.9(18 \%)$ & $22.0(27 \%)$ \\
\hline
\end{tabular}

\footnotetext{
a The yield is significantly different from control with a risk $\alpha=5 \%$.
} 

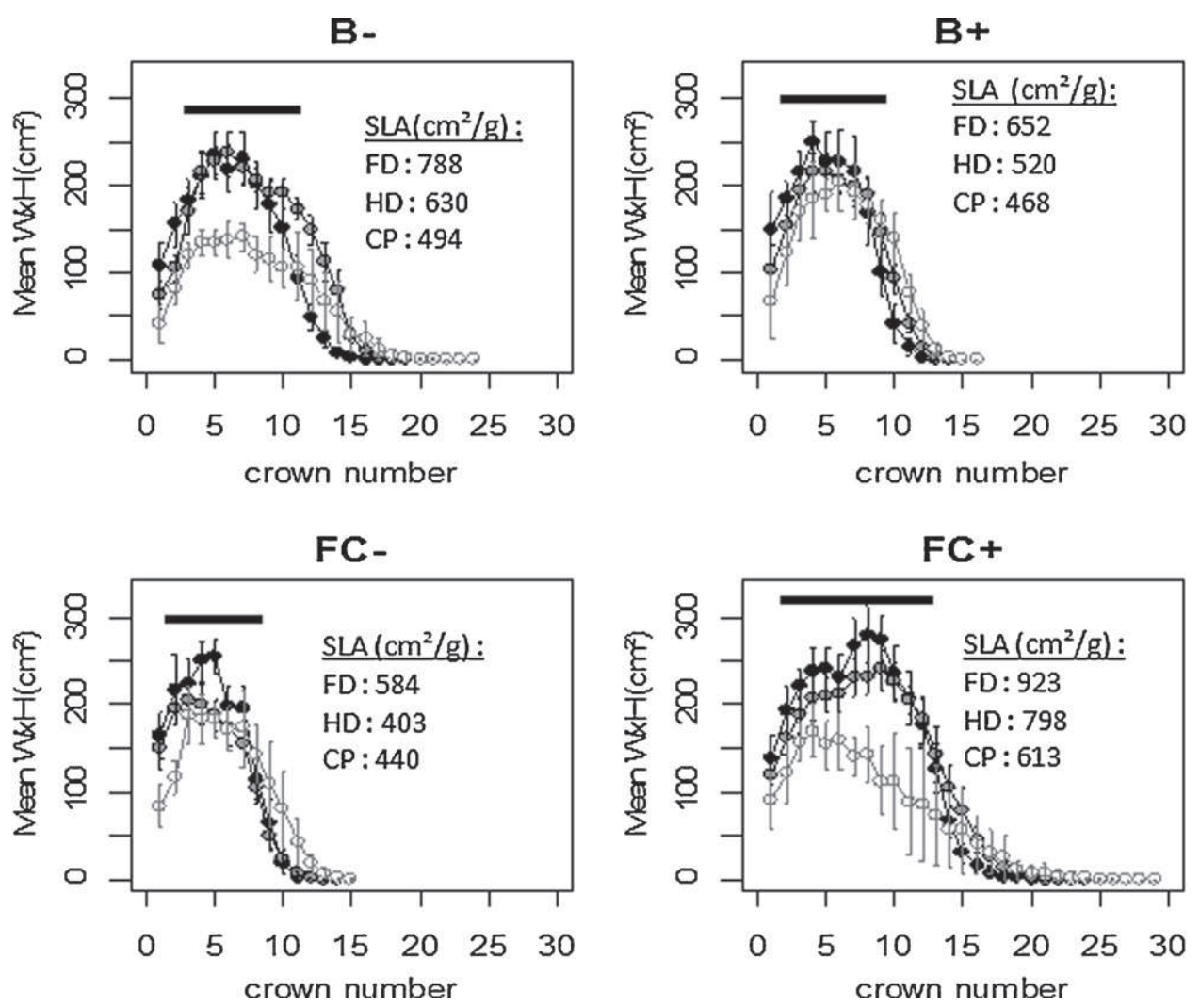

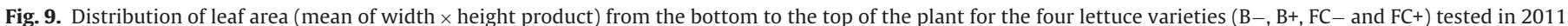

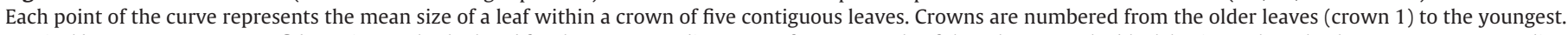

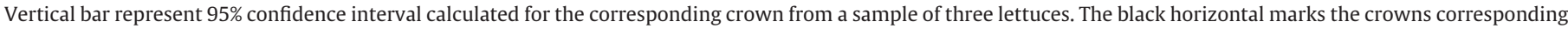
to mature leaves.

to the mean length of the mature leaves (Fig. 9). We found that these leaves are both wider and longer in the shade than in the full sun. Changes in leaf angle (i.e. the angle between the soil and the leaf midrib) in lettuce head could also be responsible for differences in CR. Leaf angle reduction in response to shading was reported for grasses intercropped in orchards (Peri et al., 2007), as a direct consequence of leaves getting both longer and thinner, and thus less rigid under shade. Lettuces with a leaf angle close to horizontal orientation would be able to cover a largest proportion of ground and therefore to intercept more light. Similarly, Wurr et al. (1992) reported lettuce heads to be less tight when plant are submitted to high levels of solar radiation in the second part of the cycle (after hearting). In 2011, we observed that plant axes were significantly taller and thinner in the shade $(7.4 \mathrm{~cm}$ and $2.0 \mathrm{~g}$ of dry matter per axis) compared to full sun $(6.6 \mathrm{~cm}$ and $2.5 \mathrm{~g}$ per axis). Changes in axis shape could also have contributed to leaf crown being looser and more horizontal.

4.1.2.2. Reducing self shading. Different adjustments were fitted to CR as a function of thermal time, in the shade and in full sun. In 2010, the inflexion point of the curve (represented by the $\mu$ parameter in Eq. (8) and Table 1) is reached earlier in the shade for variety FC+, which seems to be the more shade tolerant. According to Holsteijn (1980), it denotes a reduction of self-shading and mutual shading with neighboring lettuces. Self-shading refers to leaves of the same plant shading each other and increases when the lettuce leaves twist and turn. This result is consistent with the finding of Bensink (1971), that shading encourages the elongation of leaf's central vein at the expense of lamina expansion, creating spoonshape leaves.

\subsection{Perspective for optimizing photovoltaic system}

\subsubsection{Adequate level of shading by PVPS}

Our results show that under an AVA with half the number of PVPs, lettuce yield was hardly affected. Under a standard AVA with the full density of PVPs, lettuce yield was strongly reduced, down to $48 \%$ of the potential yield in the full sun for most of the varieties. If lettuce production is expected to be not significantly reduced, then the AVA should be designed to allow at least $70 \%$ of $\mathrm{PAR}_{0}$ at the crop level (HD design). A smart suggestion to maintain a high level of electricity production would be to mount the PVPs on a mobile structure that would allow a change in the tilting angle of the panels. This would help to monitor light transmission under the panels to maintain it above the required threshold. Between cropping periods, or when the crops need less radiation, PVPs could be set back to their optimum position for maximal electricity production. It could be possible to calculate the year production of electricity and crop products resulting from such a management, and to optimize the settings taking into account the cash value of both electricity and crop products.

Decreasing the density of panels (as tested in our experimental array) is another option, but it is less flexible: this will lead to reduce the electric productivity of the PVP layer for the whole year, including when crops are not present. Comparing the two options (mobile panels versus reduced density of panels) would also require to take into account the investments into the array, which are higher for a FD array (including the cost of mobile panels) than for a HD array.

Finally, the productivity of agrivoltaic system should be tested on longer periods, in order to assess if this production system is economically and environmentally sustainable. Our experiment includes other vegetable species (beans, cucumber) as well as cereal crops (durum wheat). Spring, summer and autumn crops 


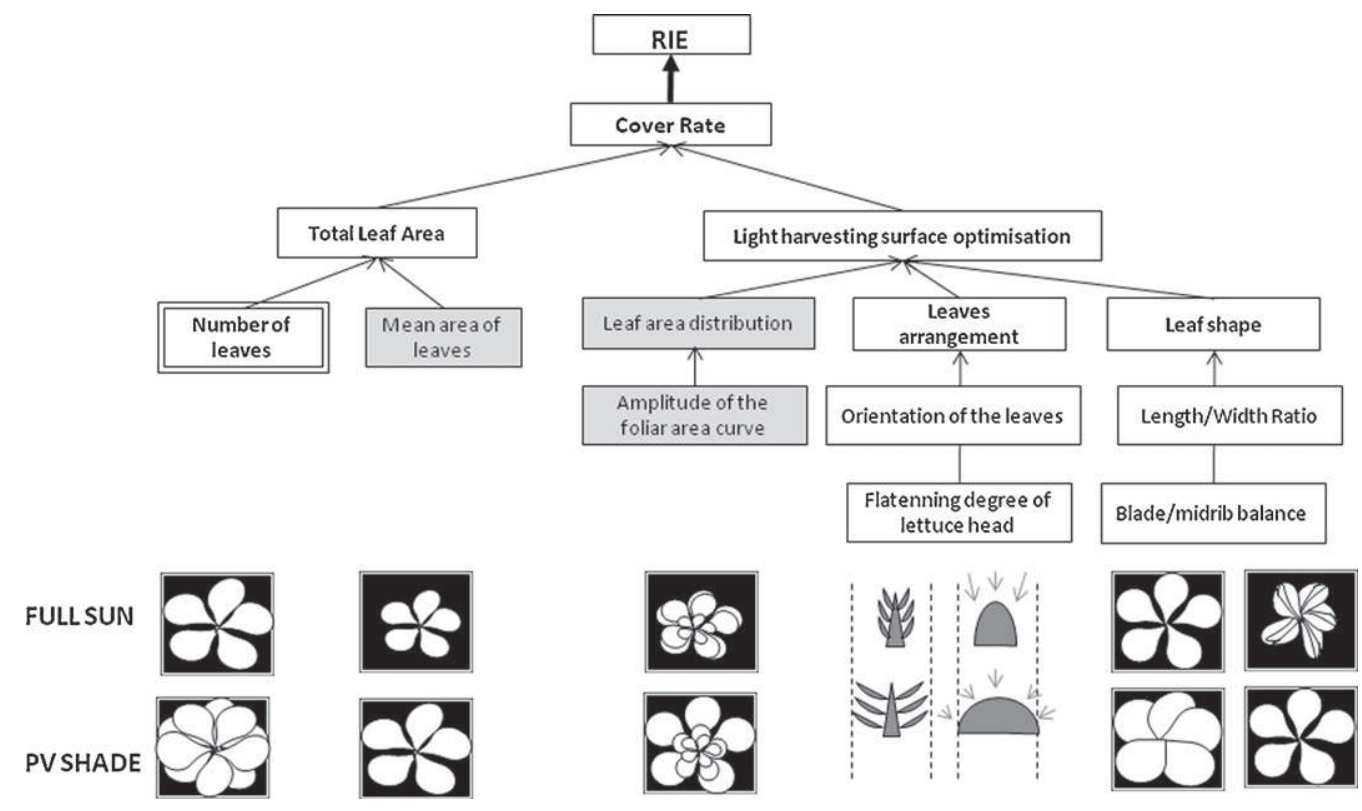

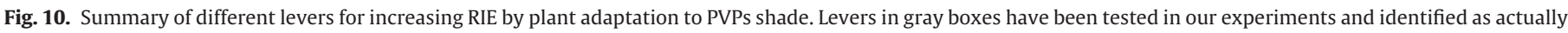
playing a role in the response to shade. Levers with a double thin border have been showed not to participate in shade tolerance.

may behave differently in the shade of solar PVs. Their combination in proper rotation will also be needed to ensure a sustainable management of weeds, pest and disease and soil quality. Therefore, a comprehensive assessment of these agrivoltaic systems will require a multicriteria analysis of crop rotations.

\subsubsection{Toward a selection of specific plant traits for agrivoltaic systems}

The different varieties tested in the two seasons (summer in 2010 and spring in 2011) responded differently to the same level of shade created by PVPs. In 2011, varieties FC+ and B- appeared to be much more tolerant to shade. This result suggests that functional traits for shade tolerance could be identified (Fig. 10) in order to select adapted genotypes for agrivoltaic systems. Current literature on shade tolerance mainly focuses on RCE and points out net photosynthetic rate, leaf mass area, leaf chlorophyll content, or leaf life-span as indicators of shade tolerance (Hallik et al., 2009; Niinemets, 2010; Poorter et al., 2009; Poorter, 2001; Seidlova et al., 2009). However, we showed that RCE, which is likely to be affected by these traits, is not the main lever of adaption to shade for lettuces. Our results suggest that adaptative traits of leaf development and expansion could lead to an increased RIE in PVPs shade which could compensate for reduced light availability. As summarized in Fig. 10, total plant leaf area, cover rate and the harvesting light ability through adaptive leaf morphology are the main levers for the plant to handle light reduction by PVPs. In $\mathrm{HD}$, varieties $\mathrm{FC}+$ and $\mathrm{B}-$ exhibited significant modification of leaf area distribution (Fig. 9) and kept final yields similar to yields in the full sun. At the same time, these two varieties had the lowest individual leaf area in the full sun (Fig. 9), indicating the strong adaptive nature of leaf area to light availability in these varieties. This suggest that the selection of varieties adapted to agrivoltaic systems should not be based on leaf growth potential in the full sun, but on their plasticity in the specific shade conditions created by PVPs panels (i.e. intermittent light during the day) which are likely to be different to partial but continuous shade.

\section{Conclusion}

To our knowledge this work is the first attempt to analyze plant production in the specific conditions of shade created by the PVPs of an agrivoltaic system. It shows that some plants like lettuce have the ability to adapt to these conditions and compensate partially or totally the reduction of light availability by a higher light harvesting capability. We were able to relate this adaptive behavior to morphological changes in leaf development and morphology. Similar work is conducted with other species (cucumber, French beans and durum wheat) (Marrou, PhD thesis) in order to identify crop rotations adapted to these conditions. Our results suggest that these agrivoltaïc systems can be optimized both by plant breeding and by specific arrangements of PVPs panels in order to find the best compromise between food production and electricity production on the same piece of land. In this sense, this work opens the scope for an integrated design of agrivoltaic systems to optimize food and energy production in a given economic context.

\section{Acknowledgements}

The authors gratefully acknowledge the Sun'R society for funding this research project. Special acknowledgments are dedicated to the technical staff (J.F. Bourdoncle, A. Sellier, P. Parra), and trainees (A. Legendre, E. de Mondenard, A. Calvet, and A. François) for their essential contribution to data collection in the field. Thanks to $\mathrm{G}$. Talbot (INRA, Montpellier, France) for his help in simulating radiation, M. Tchamitchian (INRA, Avignon, France) for his advice in ecophysiology, N. Hilgert (INRA, Montpellier, France) for her help on gnls adjustments, and P. Ruelle (IRSTEA, Montpellier, France) for his support all along the two experimental campaigns.

\section{Appendix A. Radiation model mathematical formalisms}

\section{A.1. Part A: Building a sky map, at daily time step}

The first part of the model uses measured mean daily global radiation (Gr) to create a sky map for every day of the period during which the simulation will be run. The sky is divided into sectors with an angle step $\alpha$ fixed by the user (we ran the simulations with an angle step $\alpha=5^{\circ}$ ). Each sky sector is defined by the azimuth (az) and the elevation (el) of its central beam. 
The model distributes diffuse, direct and total Gr among sky sectors. The global radiation $\mathrm{Gr}_{\mathrm{az}, e l, d}$ coming from a sector(az, el), for the day $d$, is calculated from Eq. (A.1)

$\mathrm{Gr}_{\mathrm{az}, e l, d}=\mathrm{Gr}_{d} \times\left(\mathrm{PDIF}_{d} \times \mathrm{DIF}_{e l}+\left(1-\mathrm{PDIF}_{d}\right) \times \mathrm{DIR}_{\mathrm{az}, e l, d}\right)$

where

$$
\begin{cases}W_{e l, \mathrm{az}, t}=2 \times\left[\operatorname{acos}\left(\frac{\Omega_{e l, \mathrm{az}, t}}{r}\right) \times r^{2}-\left(\sqrt{\left(r^{2}-\Omega_{e l, \mathrm{az}, t}^{2}\right)} \times \Omega_{e l, \mathrm{az}, t}\right)\right] & \text { if } \Omega_{e l, \mathrm{az}, t} \leq r \\ W_{e l, \mathrm{az}, t}=0 & \text { if } \Omega_{e l, \mathrm{az}, t}>r\end{cases}
$$

[1 ]PDIF $_{d}$ is the ratio of diffuse radiation RGdif, ${ }_{d}$ above the glogal radiation $\mathrm{Gr}_{d}$ for the day $d$. $\mathrm{PDIF}_{d}$ is given by Eq. (A.2) (VarletGrancher, 1975).

$$
\left\{\begin{array}{l}
\mathrm{PDIF}_{d}=1.3-1.2 \times \frac{\mathrm{Gr}_{d}}{\mathrm{GO}_{d}} \\
0.01 \leq \mathrm{PDIF}_{d} \leq 1
\end{array}\right.
$$

with $\mathrm{GO}_{d}$ the extraterrestrial radiation for the day $d$.

$\mathrm{GO}_{d}$ is calculated according to FAO 56 (Allen et al., 1998) formalism (Eq. (A.3)).

$$
\begin{aligned}
G 0_{d}=\frac{24 \times 60}{\pi} & \times G_{s c} \times d_{r}[\omega \times \sin (\phi) \times \sin (\delta)+\cos (\phi) \times \cos (\delta) \\
& \times \sin (\omega)]
\end{aligned}
$$

with $G_{\mathrm{sc}}$ : solar constant. $G_{\mathrm{sc}}=0.0820 \mathrm{MJ} \mathrm{m}^{-2} \mathrm{~min}^{-1}$.

$d_{r}$ inverse relative distance Earth Sun $[\mathrm{m}] d_{r}=1+0.0033$

$$
\times \cos \left(\frac{2 \pi}{365} d\right)
$$

$\omega$ : sunset hour angle [rad]. $\omega=\operatorname{arcos}(-\tan (\phi) \times \tan (\delta))$ (A.5)

$\varphi$ : latitude [rad].

$\delta$ : solar decimation [rad]. $\delta=0.409 \times \sin \left(\frac{2 \pi}{365} \times d-1.39\right)$

[2 $]_{\mathrm{DIF}}$ is the proportion of diffuse radiation incoming from each sky sector (az, el). As sky was discretized following a Standart Overcast Sky (SOC) distribution, as described by Moon and Spencer, 1942, DIF only depends on the sky sector elevation.

$$
\begin{aligned}
\mathrm{DIF}_{e l}=\frac{6}{7} & \times n \times\left[\frac{\left(\sin (e l+(\alpha / 2))^{2}-\left(\sin (e l-(\alpha / 2))^{2}\right.\right.}{2}\right. \\
& \left.+2 \times \frac{\left(\sin (e l+(\alpha / 2))^{3}-\left(\sin (e l-(\alpha / 2))^{3}\right.\right.}{3}\right]
\end{aligned}
$$

with $n$ the number of sky sectors.

[3 ]DIR $_{e l, \mathrm{az}, d}$ is the proportion of diffuse radiation incoming from each sky sectors $(a z, e l)$, for the day $d$. This fraction of the daily radiation is incoming from the sun direction in two steps: (1) sun position is calculated and direct radiation is allocated to sky sectors close to the sun position with a time step inferior or equal to $1 \mathrm{~h}$ and (2) the direct radiation is integrated over the day length for each sky sector.

Time step must be coherent with angle step: small angle step requires short time steps. We ran the calculations with a time step of $20 \mathrm{~min}$.

$\operatorname{DIR}_{e l, \mathrm{az}, d}=\sum_{t=\text { sunrise }}^{t=\text { sunset }}\left(\frac{\sin \left(\theta_{s, t}\right)}{\sum_{t=\text { sunrise }}^{t=\text { sunset }} \sin \left(\theta_{s, t}\right)} \times \frac{W_{e l, \mathrm{az}, t}}{\sum_{e l, \mathrm{az}} W_{e l, \mathrm{az}, t}}\right)$

with with

$\theta_{s, d}$ the sun declination at time $t$, calculated according Allen et al. (1998), as well as sunrise and sunset times

$W_{e l, a z, t}$ a weighting term that distributes the direct energy among the sky sectors that are the closest to the sun position. $W_{e l, a z, t}$ is equal to the intersection of the sky sector $(e l, a z)$ with a disk of solid angle equal to $2 \pi / n$ ( $n$ : number of sectors), centered

$$
\begin{array}{r}
\Omega_{e l, \mathrm{az}, t}=\operatorname{acos}\left(\frac{\cos \left(\left\|\mathrm{az}-\mathrm{az}_{s, t}\right\|\right) \times \cos \left(\left\|e l-e l_{s, t}\right\|\right)}{2}\right) \\
\text { and } \| \mathrm{az}-\mathrm{az}_{s} \text { and }\left\|\mathrm{az}-\mathrm{az}_{s, t}\right\| \operatorname{in}[-\pi ; \pi]
\end{array}
$$

$$
r=\operatorname{acos}\left(1-\frac{1}{n}\right)
$$

$\mathrm{az}_{s, t}$ is the sun azimuth at time $t$, calculated according to Allen et al. (1998); $e l_{s, t}$ is the sun elevation at time $t$, calculated according to Allen et al. (1998).

\section{A.2. Part B: sorting intercepted and non intercepted beams}

The simulated scene is 3D is orientated in a 3D orthogonal referential. $x$ axis is parallel to North-South direction, pointing South (azimuth=0), $y$ axis is pointing East, and $y$ axis is pointing the Zenith.

For $k$ varying from 1 to the number of PVPs strips Np, PVP strip $k$ is defined as a finite plane of Eq. (B.1).

$P_{k}:(x, y, z) /\left\{\begin{array}{l}\sin (\gamma) \times\left(x-D_{k}\right)+\cos (\gamma) \times(z-h)=0 \\ h \leq z \leq h+l \times \sin (\gamma) \\ y 0 \leq y \leq y 0+m\end{array}\right.$

where $\gamma$ is the tilt angle of the PVP strips from the horizontal level [rad]; $D_{k}$ is the position of the southern edge of PVP strip $k$ [m] $D_{k}=x 0+(k-1) \times e$, where $x 0$ is the position of the first PVP strip (southern edge) on the North South axis, and $e$ is the distance between 2 PVP strips. $h$ is the height of the PVP strips (bottom edge); $y 0$ is the position of the Eastern end of the PVP strips along the East-West axis.

Rays incoming from sky sector (az, el) and hitting the ground at the location $\left(x_{M}, y_{M}, 0\right)$ are assimilated to straight lines coming from the center of the sky sector. They are defined by Eq. (B.2).

$$
\mathcal{D}_{\mathrm{az}, e l, M}:(x, y, z) / \exists \tau \in \mathbb{R} /\left\{\begin{array}{l}
x-x_{M}=\frac{\cos (\mathrm{az})}{\tan (e l)} \times \tau \\
y-y_{M}=-\frac{\sin (\mathrm{az})}{\tan (e l)} \times \tau \\
z=\tau
\end{array}\right.
$$

Transmitted radiation $\operatorname{Tr}_{d}$ for the day $\mathrm{d}$ at the position $\left(x_{M}, y_{M}\right.$, 0 ) for the day $d$ is calculated as the sum of the rays that are not intercepted by any of the PVP strips.

$$
\operatorname{Tr}_{M}=\sum_{D_{\mathrm{az}, e l, M} \in T_{M}} G r_{\mathrm{az}, e l}
$$


where $T_{M}$ is the pool of rays hitting ground at the location $\left(x_{M}, y_{M}\right.$,

0 ), and that are not intercepted by any PVP strips.

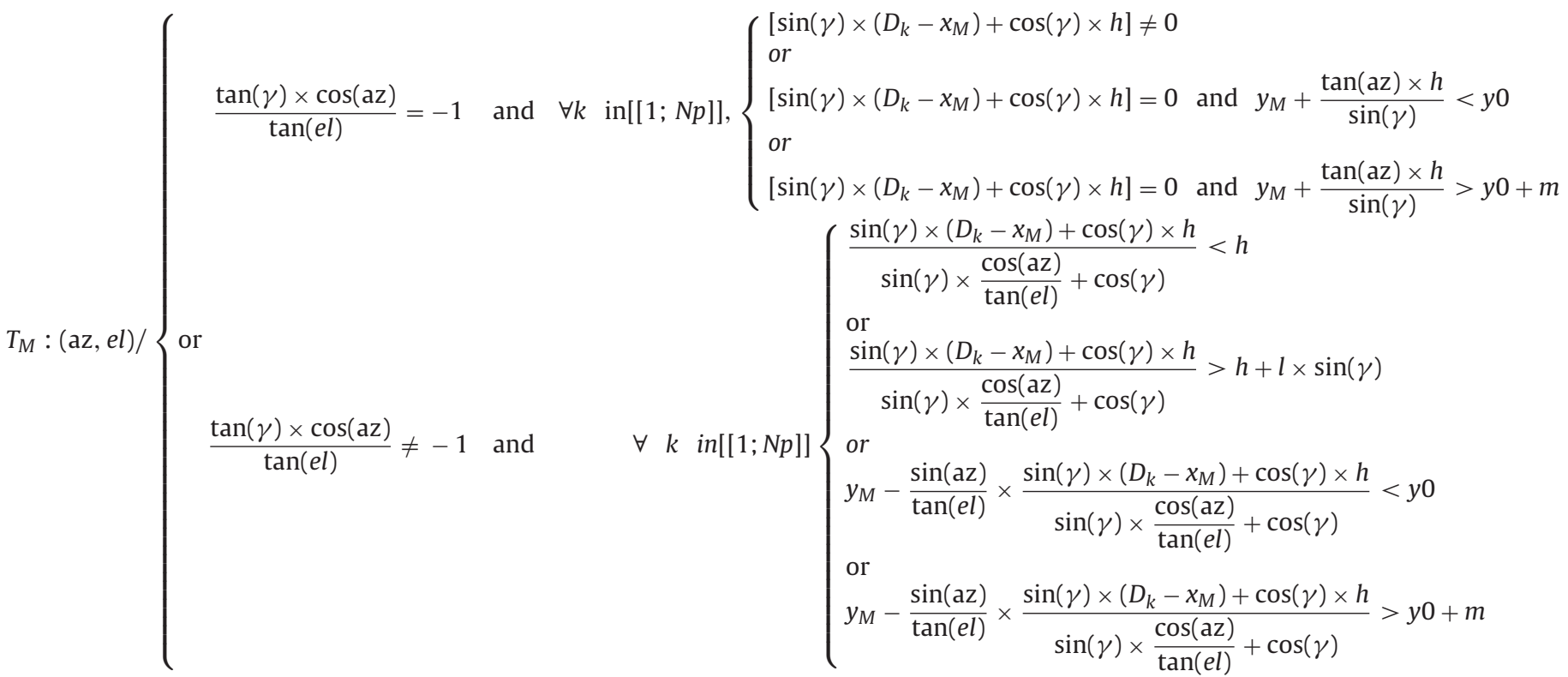

\section{References}

Allen, R.G., Pereira, L.S., Raes, D., Smith, M., 1998. Crop Evapotranspiration - Guidelines for Computing Crop Water Requirements. FAO - Food and Agriculture Organization of the United Nations, Rome.

Bensink, J., 1971. On Morphogenesis of Lettuce Leaves in Relation to Light and Temperature. PhD thesis. Veenman University, Wageningen.

Cantagallo, J.E., Medan, D., Hall, A.J., 2004. Grain number in sunflower as affected by shading during floret growth, anthesis and grain setting. Field Crops Research 85 (2-3), 191-202.

Dapoigny, L., De Tourdonnet, S., Roger-Estrade, J., Jeuffroy, M.-H., Fleury, A., 2000. Effect of nitrogen nutrition on growth and nitrate accumulation in lettuce (Lactuca sativa L.), under various conditions of radiation and temperature. Agronomie 20, 843-855.

De Tourdonnet, S., 1998. Maîtrise de la qualité et de la pollution nitrique en production de laitues sous abris plastique: diagnostic et modélisation des effets des sytèmes de culture. In: Unité d'Agronomie Paris-Grignon, Institut National Agronomique de Paris-Grignon, Paris-Grignon, pp. 191.

Dupraz, C., Marrou, H., Talbot, G., Dufour, L., Nogier, A., Ferard, Y., 2010. Combining solar photovoltaic panels and food crops for optimising land use: towards new agrivoltaic schemes. Renewable Energy 36 (10), 2725-2732.

Escobar, J.C., Lora, E.S., Venturini, O.J., Yanez, E.E., Castillo, E.F., Almazan, O., 2009. Biofuels: environment, technology and food security. Renewable and Sustainable Energy Reviews 13 (6-7), 1275-1287.

Frazer, G.W., Canham, C.D., Lertzman, K.P., 1999. Gap Light Analyzer (GLA), Version 2.0: Imaging Software to Extract Canopy Structure and Gap Light Transmission Indices from True-Colour Fisheye Photographs. In: Users manual and program documentation, Simon Fraser University, Burnaby, British Columbia, and the Institute of Ecosystem Studies, Millbrook, New York.

Gay, F., 2002. Elaboration d'une méthode d'évaluation des risques de pollution nitrique et de pertes de rendement en parcelles agricoles $\mathrm{PhD}$ thesis. Ecole Nationale Supérieure Agronomique de Montpellier, Montpellier, pp. 237.

Gimenez, C., Otto, R.F., Castilla, N., 2002. Productivity of leaf and root vegetable crops under direct cover. Scientia Horticulturae 94 (1-2), 1-11.

Goaetzberger, A., Zastrow, A., 1982. On the coexistence of solar-energy conversion and plant cultivation. International Journal of Solar Energy 1 (1), 55-69.

Hallik, L., Niinemets, U., Wright, I.J., 2009. Are species shade and drought tolerance reflected in leaf-level structural and functional differentiation in Northern Hemisphere temperate woody flora? New Phytologist 184 (1), 257-274.

Holsteijn, H.M.C., 1980. Growth of Lettuce. I. Covering of Soil Surface. Veenman, Wageningen.

Hoogwijk, M., Faaij, A., Van Den Broek, R., Berndes, G.R., Gielen, D., Turkenburg, W., 2003. Exploration of the ranges of the global potential of biomass for energy. Biomass and Bioenergy 25 (2), 119-133.

Hunt, R., Wilson, J.W., Hand, D.W., Sweeney, D.G., 1984. Integrated Analysis of Growth and Light Interception in winter lettuce I. Analytical methods and environmental influences. Annals of Botany 54 (6), 743-757.

Kitaya, Y., Niu, G., Kozai, T., Ohashi, M., 1998. Photosynthetic photon flux, photoperiod, and $\mathrm{CO}_{2}$ concentration affect growth and morphology of lettuce plug transplants. HortScience 33 (6), 988-991.
Ku, H., 1966. Notes on the use of propagation of error formulas. Journal of Research of National Bureau of Standards - C Engineering and Instrumentation 70C (4), 263-273.

Monteith, J.L., 1972. Solar radiation and productivity in tropical ecosystems. Journal of Applied Ecology 9, 747-766.

Monteith, J.L., 1977. Climate and the efficiency of crop production in Britain. Philosophical Transactions of the Royal Society 281, 277-294.

Niinemets, U., 2010. A review of light interception in plant stands from leaf to canopy in different plant functional types and in species with varying shade tolerance. Ecological Research 25 (4), 693-714.

Nonhebel, S., 2005. Renewable energy and food supply: will there be enough land? Renewable and Sustainable Energy Reviews 9 (2), 191-201.

Pellegrino, A., Gozé, E., Lebon, E., Wery, J., 2006. A model-based diagnosis tool to evaluate the water stress experienced by grapevine in field sites. European Journal of Agronomy 25 (1), 49-59.

Peri, P.L., Moot, D.J., Jarvis, P., Mcneil, D.L., Lucas, R.J., 2007. Morphological, anatomical, and physiological changes of orchardgrass leaves grown under fluctuating light regimes. Agronomy Journal 99 (6), 1502-1513.

Pimentel, D., Marklein, A., Toth, M., Karpoff, M., Paul, G., Mccormack, R., Kyriazis, J., Krueger, T., 2009. Food versus biofuels: environmental and economic costs. Human Ecology 37 (1), 1-12.

Poorter, H., Niinemets, Ü., Poorter, L., Wright, I.J., Villar, R., 2009. Causes and consequences of variation in leaf mass per area (LMA): a meta-analysis. New Phytologist 182 (3), 565-588.

Poorter, L., 2001. Light-dependent changes in biomass allocation and their importance for growth of rain forest tree species. Functional Ecology 15 (1), $113-123$.

Rathmann, R.G., Szklo, A., Schaeffer, R., 2007. Land use competition for production of food and liquid biofuels: an analysis of the arguments in the current debate. Renewable Energy 35 (1), 14-22.

Rizzalli, R.H., Villalobos, F.J., Orgaz, F., 2002. Radiation interception, radiation-use efficiency and dry matter partitioning in garlic (Allium sativum L.). European Journal of Agronomy 18 (1-2), 33-43.

Ruelle, P., 1995. Variabilité spatiale à l'échelle de parcelles de cultures: étude expérimentale et modélisation des bilans hydriques et des rendements. PhD thesis. Laboratoire desTransferts en Hydrologie et Environnement. CEMAGREF Division Irrigation Montpellier, Université Joseph Fourier - Grenoble I, Grenoble, pp. 210.

Seber, G.A.F., Wild, C.J., 2003. Nonlinear Regression. Wiley-Interscience, John Wiley \& Sons, Inc, Hobooken NJ, USA, pp. 753.

Seidlova, L., Verlinden, M., Gloser, J., Milbau, A., Nijs, I., 2009. Which plant traits promote growth in the low-light regimes of vegetation gaps? Plant Ecology 200 (2), 303-318.

Sinclair, T.R., Muchow, R.C., Donald, L.S., 1999. Radiation use efficiency. In: Advances in Agronomy. Academic Press, Newark, DE, USA, pp. 215-265.

Tei, F., Scaife, A., Aikman, D.P., 1996. Growth of lettuce, onion, and red beet. 1. Growth analysis, light interception, and radiation use efficiency. Annals of Botany 78 (5), 633-643.

Thicoïpé, J.P., 1997. Laitues. CTIFL SERAIL, Paris. pp 280. 
Tilman, D., Socolow, R., Foley, J.A., Hill, J., Larson, E., Lynd, L., Pacala, S., Reilly, J., Searchinger, T., Somerville, C., Williams, R., 2009. Beneficial biofuels: the food, energy, and environment trilemma. Science 325 (5938), 270-271.

Varlet-Grancher, C., 1975. Variation et estimation de l'énergie reçue sur des plans d'inclinaison et d'azimut variables. Annals of Agronomy 26, 245-264.

Wacquant, C., Zuang, H., Baille, A., 1995. Maîtrise de la conduite climatique: tomate sous serre et abris en sol et hors sol, Paris.

Walker, D.A., 2009. Biofuels - for better or worse? Annals of Applied Biology 156 (3), 319-327.
Wilson, P.J., Thompson, K.E.N., Hodgson, J.G., 1999. Specific leaf area and leaf dry matter content as alternative predictors of plant strategies. New Phytologist $143(1), 155-162$.

Worku, W., Skjelvåg, A.O., Gislerød, H.R., 2004. Responses of common bean (Phaseolus vulgaris L.) to photosynthetic irradiance levels during three phenological phases. Agronomie 24, 267-274.

Wurr, D.C.E., Fellows, J.R., Hambridge, A.J., 1992. Environmental-factors influencing head density and diameter of crisp lettuce Cv saladin. Journal of Horticultural Science 67 (3), 395-401. 